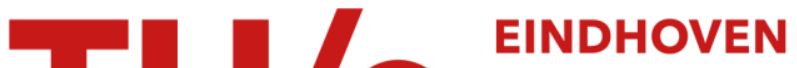 UNIVERSITY OF TECHNOLOGY
}

\section{Ab initio study of isotropic and anisotropic hyperfine interactions in phosphoranyl and phosphorane anion radicals}

\section{Citation for published version (APA):}

Janssen, R. A. J., \& Buck, H. M. (1984). Ab initio study of isotropic and anisotropic hyperfine interactions in phosphoranyl and phosphorane anion radicals. Journal of Molecular Structure: THEOCHEM, 19(1-2), 139-153. https://doi.org/10.1016/0166-1280(84)80121-9

DOI:

10.1016/0166-1280(84)80121-9

Document status and date:

Published: 01/01/1984

\section{Document Version:}

Publisher's PDF, also known as Version of Record (includes final page, issue and volume numbers)

\section{Please check the document version of this publication:}

- A submitted manuscript is the version of the article upon submission and before peer-review. There can be important differences between the submitted version and the official published version of record. People interested in the research are advised to contact the author for the final version of the publication, or visit the $\mathrm{DOI}$ to the publisher's website.

- The final author version and the galley proof are versions of the publication after peer review.

- The final published version features the final layout of the paper including the volume, issue and page numbers.

Link to publication

\section{General rights}

Copyright and moral rights for the publications made accessible in the public portal are retained by the authors and/or other copyright owners and it is a condition of accessing publications that users recognise and abide by the legal requirements associated with these rights.

- Users may download and print one copy of any publication from the public portal for the purpose of private study or research.

- You may not further distribute the material or use it for any profit-making activity or commercial gain

- You may freely distribute the URL identifying the publication in the public portal.

If the publication is distributed under the terms of Article 25fa of the Dutch Copyright Act, indicated by the "Taverne" license above, please follow below link for the End User Agreement:

www.tue.nl/taverne

Take down policy

If you believe that this document breaches copyright please contact us at:

openaccess@tue.nl

providing details and we will investigate your claim. 


\title{
AB INITIO STUDY OF ISOTROPIC AND ANISOTROPIC HYPERFINE INTERACTIONS IN PHOSPHORANYL AND PHOSPHORANE ANION RADICALS
}

\author{
RENÉ A. J. JANSSEN and HENK M. BUCK \\ Department of Organic Chemistry, Eindhoven University of Technology, Eindhoven \\ $5600 \mathrm{MB}$ (The Netherlands)
}

(Received 15 March 1984)

\begin{abstract}
A detailed ab initio study of isotropic and anisotropic hyperfine couplings (hfc) is presented for the $\dot{\mathrm{PH}}_{4}\left(C_{2 \mathrm{v}}, C_{3 \mathrm{v}}\right), \dot{\mathrm{PF}}_{4}\left(C_{2 \mathrm{v}}, C_{3 \mathrm{v}}\right)$ and $\mathrm{PF}_{3}-\left(C_{4 \mathrm{v}}\right)$ radicals. Unrestricted Hartree-Fock (UHF), optionally with annihilation of the largest spin contaminant (UHF + AN), and restricted open-shell Hartree-Fock (ROHF) calculations are used to obtain electronic wave functions which describe doublet states. Throughout a 4-31G basis set is used and the influence of the implementation of $d$-type Gaussians on phosphorus is evaluated. All studied quantum chemical methods give good results for the isotropic hfc. Anisotropic hfes are in good agreement with the experimental data only if the wave function describes a pure doublet state. The inclusion of $d$-functions leads to a serious decrease of the hyperfine interactions of the apical ligands in the $C_{2 \mathrm{v}}$ radicals and the equatorial ligands in the $C_{3 \mathrm{v}}$ radicals. The calculations clearly show that the fluorine dipolar hfe for the two $\dot{\mathrm{PF}}_{4}$ isomers and the $\dot{\mathrm{PF}}_{5}^{-}$radical is not directed along the corresponding $P-F$ linkage, but makes a pronounced angle $\left(\approx 25^{\circ}\right)$ with this bond.
\end{abstract}

\section{INTRODUCTION}

Many phosphoranyl $\left(\dot{\mathrm{PX}}_{4}\right)$ and phosphorane anion $\left(\mathrm{PXX}_{5}^{-}\right)$radicals have been investigated by electron spin resonance (ESR) spectroscopy. It was shown that phosphoranyl radicals can adopt different conformations depending on the ligands attached to phosphorus and steric constraints of ring structures [1]. From a number of single crystal ESR studies information was obtained for isotropic and anisotropic hyperfine coupling (hfc) [2-5]. From the isotropic hfc the participation of the valence $s$ orbitals in the molecular orbitals can be estimated, whereas the anisotropic hfc can be related to the contribution of $p$ (and $d$ ) orbitals. This results in a description of the singly occupied molecular orbital (SOMO). Previous ab initio calculations using the unrestricted Hartree-Fock (UHF) theory have been moderately successful in predicting isotropic hfes for phosphoranyl [6, 7] and related radicals with other second row central atoms $[8,9]$. In these calculations orbital populations derived from a Mulliken population analysis are compared with the estimated values from the experimental hfc. In the present 
study ab initio calculations are presented for isotropic and anisotropic hfcs, obtained by computing the expectation values of the corresponding operators. The calculations are performed for a number of elementary phosphoranyl and phosphorane anion radicals. A comparison is made with experimental values and the influence of $d$ orbitals on phosphorus is evaluated.

\section{QUANTUM CHEMICAL METHODS}

\section{Electronic wave function}

Three quantum chemical procedures were used to obtain a wave function for the open-shell state radicals. First, using the UHF method there is a serious limitation since the resulting wave function in general does not describe a pure spin state, but contains significant contaminations of higher multiplicities. Since the major aim of this study is the calculation of spindependent properties it is necessary to abstract wave functions which describe the doublet state more accurately. Therefore the UHF procedure was followed by removal of the next possible spin multiplicity (i.e., the quartet state). This was achieved by the use of the annihilation operator $[10,11]$. This second method is denoted as UHF + AN. Finally, the restricted openshell Hartree-Fock (ROHF) procedure was used, based on the theory by Binkley et al. [12]. The resulting wave function from a ROHF calculation presents a pure spin state which, however, is unable to explain spin polarization. The fact that this indirect spin distribution is neglected will be of minor interest since the studied radicals are $\sigma$-radicals and thus most of the experimentally observable isotropic and anisotropic hfcs are a result of direct delocalization of the unpaired electron. The ROHF procedure involves diagonalization of matrices in three subspaces: doubly occupied MOs/ empty MOs; singly occupied MOs/empty MOs and doubly occupied MOs/ singly occupied MOs, and is therefore very time consuming, especially when larger basis sets are involved. A difficulty which arose in computing ROHF wave functions was the accuracy of the initial guess. For UHF(+AN) calculations a projected Hückel guess is usually sufficient, but no convergence was achieved for the ROHF procedure when this type of guess was employed. It was found that the most convenient way to obtain SCF-convergence is the use of the $\alpha$-MO coefficients derived from an UHF calculation as initial guess for a ROHF calculation. Despite many attempts with different initial wave functions it was not possible to obtain SCF-convergence with the ROHF procedure for one of the studied radicals $\left(\dot{\mathrm{PF}}_{s}{ }^{-}\right.$, vide infra).

\section{Basis set}

Throughout the calculations we used a split valence 4-31G basis set [13]. To investigate the effect of $d$-type functions on the spin-dependent properties 
we implemented a single set of six second-order Gaussians on phosphorus with a radical exponent $\alpha$ of 0.55 . This basis set will be denoted as 4-31G(*). The choice for the exponent $\alpha=0.55$ is based on the closely related 6-31G* basis set for phosphorus [14].

\section{Molecular geometries}

The molecular geometries were fully optimized with respect to all bond lengths and bond angles within the symmetry constraints $\left(C_{2 \mathrm{v}}, C_{3 \mathrm{v}}, C_{4 \mathrm{v}}\right)$. The structure optimizations were carried out with the 4-31G UHF wave function obtained before annihilation. All subsequent calculations (UHF+ AN, ROHF and the inclusion of $d$-type Gaussians) were single point calculations. It is likely, however, that the molecular geometries are changed if reoptimized at UHF + AN or ROHF level, or after the inclusion of $d$-functions.

\section{Properties}

The hyperfine term of the Hamiltonian for a free radical in which one unpaired electron interacts with one nucleus consists of an isotropic part arising from the Fermi contact interaction and an anisotropic part due to electron-nuclear dipole interaction. These interactions can be evaluated by computing the expectation values of their corresponding operators. For the contact term this operator is given by

$H_{c}=(8 \pi / 3) g \beta g_{N} \beta_{N} \delta\left(\vec{r}_{N}\right) \vec{S} \cdot \vec{I}$

and for the anisotropic term by

$H_{\mathrm{ddp}}=-g \beta g_{\mathrm{N}} \beta_{\mathrm{N}}\left\langle\frac{\overrightarrow{\mathrm{S}} \cdot \overrightarrow{\mathrm{I}}}{r^{3}}-\frac{3(\overrightarrow{\mathrm{S}} \cdot \overrightarrow{\mathrm{r}})(\overrightarrow{\mathrm{I}} \cdot \overrightarrow{\mathrm{r}})}{r^{5}}\right\rangle$

When the MOs of the wave function are defined as linear combinations of atomic orbitals $\phi_{\mu}$, the expectation values of isotropic and anisotropic hyperfine interactions at a nucleus $\mathrm{N}$ can be expressed as

$a_{\mathrm{N}}^{\text {iso }}=(8 \pi / 3) g \beta g_{\mathrm{N}} \beta_{\mathrm{N}} \sum_{\mu, \nu} \mathrm{P}_{\mu \nu}^{\alpha-\beta}\left\langle\phi_{\mu}\left|\delta\left(\overrightarrow{\mathrm{r}}_{\mathrm{N}}\right)\right| \phi_{\nu}\right\rangle$

and

$\mathbf{B}_{p q}^{\mathrm{N}}=-g \beta g_{\mathrm{N}} \beta_{\mathrm{N}} \sum_{\mu, \nu} \mathbf{P}_{\mu \nu}^{\alpha-\beta}\left\langle\phi_{\mu}\left|\frac{r^{2} \delta_{p q}-3 p q}{r^{5}}\right| \phi_{\nu}\right\rangle$

respectively, in which $\mathrm{P}_{\mu \nu}^{\alpha-\beta}$ is the first-order spin density matrix and $p, q$ represent the spatial coordinates $x, y, z$ of the electron relative to the nucleus $\mathbf{N}$. Since the $\mathbf{B}_{p q}^{\mathrm{N}}$ matrix is symmetric $\left(\mathbf{B}_{p q}^{\mathbf{N}}=\mathbf{B}_{q p}^{\mathrm{N}}\right)$ it can always be diagonalized. After diagonalization the three principal values are obtained together with their directions relative to the $x, y, z$ coordinate system. Spin density plots of some of the radicals presented in this study were calculated by evaluating the point spin density $\rho(\overrightarrow{\mathbf{r}})$ defined as 
$\rho(\overrightarrow{\mathrm{r}})=\sum_{\mu, \nu} \mathbf{P}_{\mu \nu}^{\alpha-\beta}\left\langle\phi_{\mu}|\delta(\overrightarrow{\mathrm{r}})| \phi_{\nu}\right\rangle$

\section{Computational details}

The SCF calculations and structure optimizations were performed with the GAUSSIAN 80 program system [15]. This program includes optionally annihilation of the largest spin contaminant and an algorithm for the ROHF procedure. For the evaluation of the hyperfine interactions we adapted the property package of the GAUSSIAN 79 program [16] for the calculation of spin-dependent properties. The GAUSSIAN 79 property package is based on the POLYATOM program [17]. The computed values of the properties are calculated in atomic units. Conversion factors to Gauss are given in Table 1. The conversion factors include the proportionality constants of eqns. (3) and (4). The $g$-tensor is assumed to be isotropic and the actual electron $\mathrm{g}$-factor is set equal to the value $\mathbf{2 . 0 0 2 3 2}$ of the free electron.

\section{RESULTS}

The calculations were performed for the $\mathrm{PH}_{4}$ and $\mathrm{PF}_{4}$ phosphoranyl radicals both within $C_{2 \mathrm{v}}$ and $C_{3 \mathrm{v}}$ symmetry constraint and for the $\dot{\mathrm{P}} \mathrm{F}_{5}{ }^{-}$ $\left(C_{4 v}\right)$ phosphorane anion radical. Earlier work at the 4-31G level revealed the equilibrium geometries of $C_{2 v} \dot{\mathrm{PH}}_{4}$ and $C_{2 v} \dot{\mathrm{PF}}_{4}$ [6]. The optimized geometrical parameters (see Fig. 1) are presented in Table 2.

The calculated energies and the expectation values of the $S^{2}$ operator are collected in Table 3. The ROHF energies of the radicals lie 4-7 kcal mol${ }^{-1}$ above the corresponding UHF energies. The lowering of the UHF energy as a result of the inclusion of $d$-functions is approximately $45 \mathrm{kcal} \mathrm{mol}^{-1}$ for the two $\dot{\mathrm{PH}}_{4}$ radicals [18] and $90-96 \mathrm{kcal} \mathrm{mol}^{-1}$ for the $\dot{\mathrm{PF}}_{4}$ and $\dot{\mathrm{P}} \mathrm{F}_{5}^{-}$radicals. Annihilation of the largest spin contaminant results in $\left\langle S^{2}\right\rangle$ values close to 0.75 for both basis sets.

Isotropic hyperfine coupling

Isotropic hfcs have been computed for the radicals in their 4-31G UHF equilibrium geometries. The results of these calculations for the ${ }^{1} \mathrm{H},{ }^{19} \mathrm{~F}$

TABLE 1

Conversion factors to convert atomic units of isotropic and dipolar hfc to Gauss

\begin{tabular}{lcc}
\hline & Isotropic hfc & Dipolar hfc \\
\hline${ }^{1} \mathrm{H}$ & 1594.8 & 190.3 \\
${ }^{19 \mathrm{~F}}$ & 1501.2 & 179.2 \\
${ }^{31} \mathrm{P}$ & 646.2 & 77.1 \\
\hline
\end{tabular}



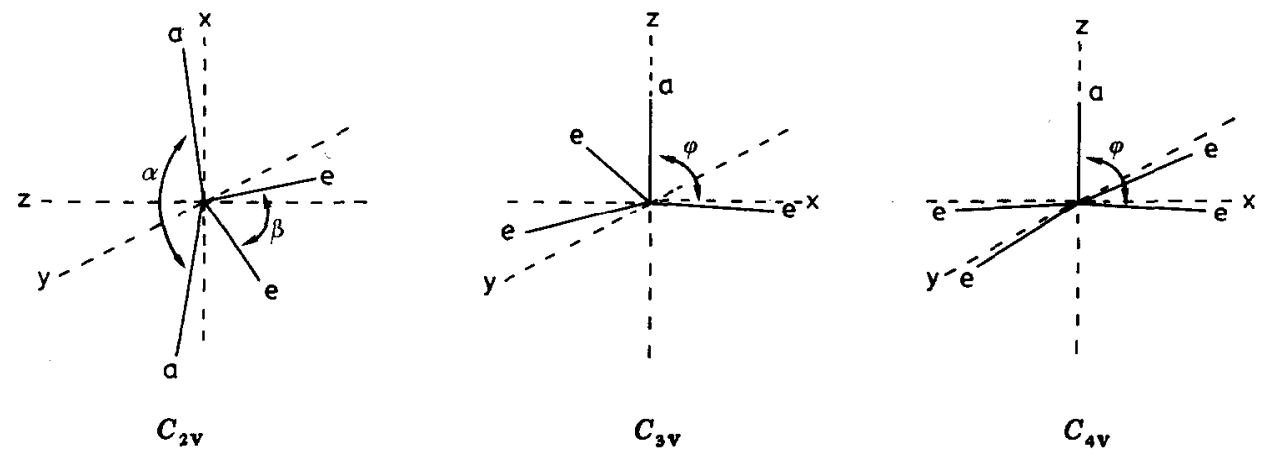

Fig. 1. Standard orientation of the $C_{2 \mathrm{v}}, C_{3 \mathrm{v}}$ and $C_{4 \mathrm{v}}$ radicals in the $x, y, z$ coordinate system. Geometrical parameters are indicated in the figures. $(a=$ apical; $e=$ equatorial).

\section{TABLE 2}

Optimized geometrical parameters (see Fig. 1) for the studied radicals

\begin{tabular}{|c|c|c|c|c|c|c|}
\hline & & \multicolumn{2}{|c|}{ Bond length (A) } & \multicolumn{3}{|c|}{ Bond angle $\left({ }^{\circ}\right)$} \\
\hline & & $r_{\mathrm{a}}$ & $r_{\mathrm{e}}$ & $\alpha$ & $\beta$ & $\phi$ \\
\hline $\begin{array}{l}\dot{\mathrm{P}} \mathrm{H}_{4} \\
\dot{\mathrm{P}} \mathrm{H}_{4} \\
\dot{\mathbf{P}} \mathbf{F}_{4} \\
\dot{\mathbf{P}} \mathbf{F}_{4} \\
\dot{\mathrm{P}} \mathbf{F}_{3}-\end{array}$ & $\begin{array}{l}C_{2 \mathrm{v}} \\
C_{\mathrm{av}} \\
C_{2 \mathrm{v}} \\
C_{3 \mathrm{v}} \\
C_{4 \mathrm{v}}\end{array}$ & $\begin{array}{l}1.648 \\
1.427 \\
1.704 \\
1.614 \\
1.640\end{array}$ & $\begin{array}{l}1.423 \\
1.590 \\
1.609 \\
1.670 \\
1.728\end{array}$ & $\begin{array}{r}172.5 \\
162.6\end{array}$ & $\begin{array}{r}97.0 \\
101.7\end{array}$ & $\begin{array}{l}89.5 \\
\\
91.6 \\
90.6\end{array}$ \\
\hline
\end{tabular}

\section{TABLE 3}

Calculated energies (a.u.) and expectation values of $S^{2}$ for the radicals in their equilibrium geometries (Table 2)

\begin{tabular}{|c|c|c|c|c|c|c|c|c|c|}
\hline & & \multicolumn{3}{|c|}{ UHF 4-31 G//4-31G } & \multicolumn{3}{|c|}{ UHF 4-31G(*)//4-31G } & \multicolumn{2}{|c|}{ R OHF $4-31 G / / 4-31 G$} \\
\hline & & $\boldsymbol{E}$ & $\left\langle S^{2}\right\rangle$ & $\overline{\left\langle S^{2}\right\rangle \mathrm{AN}}$ & $\boldsymbol{E}$ & $\left\langle S^{2}\right\rangle$ & $\overline{\left(S^{2}\right) \mathrm{AN}}$ & $\bar{E}$ & $\left(S^{2}\right)$ \\
\hline $\begin{array}{l}\dot{\mathbf{P}} \mathbf{H}_{4} \\
\dot{\mathbf{P}} \mathbf{H}_{4} \\
\dot{\mathbf{P}} \mathbf{F}_{4} \\
\dot{\mathbf{P}} \mathbf{F}_{4} \\
\dot{\mathbf{P}} \mathbf{F}_{5}^{-}\end{array}$ & $\begin{array}{l}C_{2 \mathrm{v}} \\
C_{3 \mathrm{v}} \\
C_{2 \mathrm{v}} \\
C_{3 \mathrm{~V}} \\
C_{4 \mathrm{v}}\end{array}$ & $\begin{array}{l}-342.504763 \\
-342.472475 \\
-737.556144 \\
-737.549048 \\
-836.982786\end{array}$ & $\begin{array}{l}0.8080 \\
0.8328 \\
0.7773 \\
0.7798 \\
0.7626\end{array}$ & $\begin{array}{l}0.7506 \\
0.7543 \\
0.7503 \\
0.7505 \\
0.7501\end{array}$ & $\begin{array}{l}-\mathbf{3 4 2 . 5 7 5 8 6 9} \\
-\mathbf{3 4 2 . 5 4 4 7 3 7} \\
-737.705323 \\
-737.692526 \\
-836.135765\end{array}$ & $\begin{array}{l}0.8023 \\
0.8149 \\
0.7675 \\
0.7692 \\
0.7592\end{array}$ & $\begin{array}{l}0.7511 \\
0.7530 \\
0.7502 \\
0.7503 \\
0.7501\end{array}$ & $\begin{array}{r}-342.493494 \\
-342.462516 \\
-737.548581 \\
-737.541742 \\
\text { no convergence }\end{array}$ & $\begin{array}{l}0.75 \\
0.75 \\
0.75 \\
0.75\end{array}$ \\
\hline
\end{tabular}

and ${ }^{31} \mathrm{P}$ nuclei have been summarized in Table 4 . The computed hfcs agree very well with the experimental values $[3,19,20]$. These values indicate that the SOMO of the $C_{2 v}$ radicals contains mainly contributions of phosphorus and the two apical ligands, whereas for the $C_{3 \mathrm{v}}$ and $C_{4 \mathrm{v}}$ radicals the major part of the spin density is located on phosphorus and the three (or four) equatorial nuclei. The equatorial nuclei of the $C_{2 v}$, and the apical nucleus of the $C_{3 \mathrm{v}}$ and $C_{4 \mathrm{v}}$ radicals possess a near zero spin density. Comparison of the $\left\langle S^{2}\right\rangle$ values with the calculated isotropic hfc reveals that the 


\section{TABLE 4}

Computed isotropic hfc for the nuclei of the studied radicals using different computational methods (experimental data, if available, are included)

\begin{tabular}{|c|c|c|c|c|c|c|c|c|}
\hline & & & \multicolumn{3}{|c|}{ 4-31G } & \multicolumn{2}{|c|}{$4-31 G(*)$} & \multirow[t]{2}{*}{ Experiment } \\
\hline & & & UHF & $\mathrm{UHF}+\mathrm{AN}$ & ROHF & UHF & $\mathrm{UHF}+\overline{\mathrm{AN}}$ & \\
\hline$\dot{\mathbf{P}} \mathrm{H}_{4}$ & $c_{2 v}$ & $\begin{array}{l}a_{\mathrm{P}} \\
a_{\mathrm{H}^{\mathrm{a}}} \\
a_{\mathrm{H}^{\mathrm{e}}}\end{array}$ & $\begin{array}{r}511 \\
272 \\
-15\end{array}$ & $\begin{array}{r}520 \\
212 \\
-4\end{array}$ & $\begin{array}{r}587 \\
156 \\
2\end{array}$ & $\begin{array}{r}508 \\
246 \\
-22\end{array}$ & $\begin{array}{r}533 \\
186 \\
-6\end{array}$ & $\begin{array}{l}519 \\
199 \text { (ref. 19) } \\
\quad 6\end{array}$ \\
\hline$\dot{\mathrm{P}} \mathrm{H}_{4}$ & $C_{3 v}$ & $\begin{array}{l}a_{\mathrm{P}} \\
a_{\mathbf{H}^{\mathrm{a}}} \\
a_{\mathrm{H}^{\mathrm{e}}}\end{array}$ & $\begin{array}{r}809 \\
12 \\
199\end{array}$ & $\begin{array}{r}799 \\
14 \\
135\end{array}$ & $\begin{array}{r}873 \\
17 \\
90\end{array}$ & $\begin{array}{r}690 \\
4 \\
174\end{array}$ & $\begin{array}{r}729 \\
11 \\
118\end{array}$ & \\
\hline$\dot{\mathbf{P}} \mathrm{F}_{4}$ & $C_{2 v}$ & $\begin{array}{l}a_{\mathrm{P}} \\
a_{\mathrm{F}^{\mathrm{a}}} \\
a_{\mathrm{F}} \mathrm{e}\end{array}$ & $\begin{array}{r}1089 \\
228 \\
13\end{array}$ & $\begin{array}{r}1110 \\
166 \\
13\end{array}$ & $\begin{array}{r}1190 \\
133 \\
12\end{array}$ & $\begin{array}{r}1152 \\
216 \\
23\end{array}$ & $\begin{array}{r}1162 \\
160 \\
19\end{array}$ & $\begin{array}{l}1310 \\
306 \text { (ref. 3) } \\
61\end{array}$ \\
\hline$\dot{\mathbf{P}} \mathbf{F}_{4}$ & $C_{\mathrm{sv}}$ & $\begin{array}{l}a_{P} \\
a_{F^{a}} \\
a_{F^{e}}\end{array}$ & $\begin{array}{r}1241 \\
-29 \\
228\end{array}$ & $\begin{array}{r}1271 \\
-9 \\
175\end{array}$ & $\begin{array}{r}1346 \\
-1 \\
144\end{array}$ & $\begin{array}{r}1217 \\
-15 \\
212\end{array}$ & $\begin{array}{r}1239 \\
-5 \\
165\end{array}$ & \\
\hline$\dot{\mathbf{P}} \mathbf{F}_{s}^{-}$ & $C_{4 \mathrm{v}}$ & $\begin{array}{l}a_{\mathrm{P}} \\
a_{\mathrm{Fa}} \\
a_{\mathrm{Fe}}\end{array}$ & $\begin{array}{r}1323 \\
-17 \\
174\end{array}$ & $\begin{array}{r}1341 \\
-3 \\
128\end{array}$ & & $\begin{array}{r}1269 \\
-7 \\
156\end{array}$ & $\begin{array}{r}1274 \\
-2 \\
117\end{array}$ & $\begin{array}{l}1856 \\
3 \text { (ref. 20) } \\
194\end{array}$ \\
\hline
\end{tabular}

improvement of the wave function to a more pure doublet state leads to a higher value for the isotropic hfc of the central phosphorus nucleus largely at the cost of the apical nuclei for the $C_{2 \mathrm{v}}$ radicals and the equatorial nuclei for the $C_{3 \mathrm{v}}$ and $C_{4 \mathrm{v}}$ radicals. The implementation of $d$-type functions to the 4-31G basis set leads to an increase of the isotropic hfc of the central phosphorus nucleus for $C_{2 \mathrm{v}} \dot{\mathrm{PH}}_{4}$ and $C_{2 \mathrm{v}} \dot{\mathrm{PF}}_{4}$ but lowers this value for $C_{3 \mathrm{v}} \dot{\mathrm{P}}_{4}$, $C_{3 \mathrm{v}} \mathrm{PF}_{4}$ and $C_{4 \mathrm{v}} \mathrm{PF}_{5}$. These effects are for all five radicals accompanied by a decrease of the contribution of those ligands that contribute most to the SOMO. This is more pronounced for hydrogen than for fluorine.

\section{Anisotropic hyperfine coupling}

The results of the computation of the principal values of the dipolar hfc tensor and their directions are compiled in Tables 5 to 8 for $\dot{\mathrm{PH}}_{4}, C_{2 \mathrm{v}} \dot{\mathrm{P}} \mathrm{F}_{4}$, $C_{3 \mathrm{v}} \dot{\mathrm{P}}_{4}$ and $C_{4 \mathrm{v}} \dot{\mathrm{P}} \mathrm{F}_{5}{ }_{5}^{-}$respectively. The coordinate system for these calculations is given in Fig. 1. For all radicals the $z$-axis is chosen to be the axis of highest symmetry $\left(C_{2}, C_{3}, C_{4}\right)$ and this choice corresponds with the direction of the largest principal value of the phosphorus dipolar hfc. The listed values for the two $C_{2 v}$ radicals clearly show the contaminating effect of higher multiplicities in the wave function. In an axially symmetrical system the principal values of the dipolar hfc should be in the ratio of $-\mathrm{B},-\mathrm{B}, 2 \mathrm{~B}$ 
TABLE 5

Calculated phosphorus dipolar hfe for the $C_{2 v}$ and $C_{8 v}$ isomers of the $\dot{\mathrm{P}}_{4}$ radical using different computational methods (coordinates $x, y, z$ according to Fig. 1)

\begin{tabular}{|c|c|c|c|c|c|c|c|}
\hline & & \multicolumn{3}{|c|}{$\mathrm{C}_{2 \mathrm{v}} \dot{\mathrm{PH}}_{4}$} & \multicolumn{3}{|c|}{$C_{3 v} \dot{\mathrm{PH}}_{4}$} \\
\hline & & $B_{x x}$ & $B_{y y}$ & $B_{z z}$ & $B_{x x}$ & $B_{y y}$ & $B_{z z}$ \\
\hline UHF & $4-31 G$ & -85 & 18 & 67 & -45 & -45 & 89 \\
\hline $\mathrm{UHF}+\mathrm{AN}$ & $4-31 G$ & -35 & -4 & 39 & -23 & -23 & 46 \\
\hline ROHF & $4-31 G$ & -16 & -17 & 33 & -16 & -16 & 23 \\
\hline UHF & $4-31 G\left(^{*}\right)$ & -88 & 9 & 79 & -50 & -50 & 100 \\
\hline UHF+ AN & $4-31 G(*)$ & -42 & -10 & 52 & -30 & -30 & 60 \\
\hline
\end{tabular}

TABLE 6

Calculated phosphorus and fluorine dipolar hfe (B) for $C_{2 v} \dot{P} F_{4}$ using different computational methods ${ }^{\mathrm{a}}$

\begin{tabular}{|c|c|c|c|c|c|c|c|c|c|c|c|c|}
\hline \multirow{3}{*}{$\begin{array}{l}\text { UHF } \\
\text { 4IG }\end{array}$} & \multirow[b]{3}{*}{$\begin{array}{l}B_{x x} \\
B_{y y} \\
B_{z z}\end{array}$} & \multirow{3}{*}{ 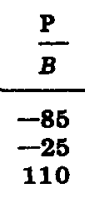 } & \multicolumn{5}{|l|}{$\mathbf{F}_{1}^{\mathbf{a}}$} & \multicolumn{5}{|l|}{$F_{1}^{\mathbf{e}}$} \\
\hline & & & \multicolumn{2}{|l|}{$B$} & \multicolumn{2}{|l|}{$T$} & \multirow{2}{*}{$\frac{\theta^{a}(\theta)}{12.7}$} & \multicolumn{2}{|l|}{$\bar{B}$} & \multirow{2}{*}{\multicolumn{2}{|c|}{ 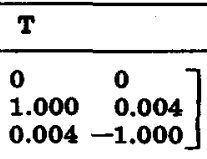 }} & $\theta^{e}(8)$ \\
\hline & & & $\begin{array}{r}335 \\
-176 \\
-177\end{array}$ & {$\left[\begin{array}{l}0.976 \\
0 \\
0.220\end{array}\right.$} & $\begin{array}{l}\mathbf{0} \\
\mathbf{1} \\
\mathbf{0}\end{array}$ & $\left.\begin{array}{l}-0.220 \\
0 \\
0.976\end{array}\right]$ & & $\begin{array}{r}-18 \\
-20 \\
38\end{array}$ & {$\left[\begin{array}{l}1 \\
0 \\
0\end{array}\right.$} & & & 0.2 \\
\hline $\begin{array}{l}\text { UHF+AN } \\
4-31 G\end{array}$ & $\begin{array}{l}B_{x x} \\
B_{y y} \\
B_{z z}\end{array}$ & $\begin{array}{r}-54 \\
-35 \\
89\end{array}$ & $\begin{array}{r}275 \\
-138 \\
-138\end{array}$ & {$\left[\begin{array}{l}0.972 \\
0 \\
0.236\end{array}\right.$} & $\begin{array}{l}\mathbf{0} \\
1 \\
\mathbf{0}\end{array}$ & $\left.\begin{array}{l}-0.236 \\
0 \\
0.972\end{array}\right]$ & 13.7 & $\begin{array}{r}-16 \\
-14 \\
29\end{array}$ & {$\left[\begin{array}{l}1 \\
0 \\
0\end{array}\right.$} & $\begin{array}{l}0 \\
0.989 \\
0.148\end{array}$ & $\left.\begin{array}{l}0 \\
0.148 \\
-0.989\end{array}\right]$ & 8.5 \\
\hline $\begin{array}{l}\text { ROHF } \\
\text { 4-31G }\end{array}$ & $\begin{array}{l}B_{x x} \\
B_{y y} \\
B_{z z}\end{array}$ & $\begin{array}{r}-45 \\
-44 \\
89\end{array}$ & $\begin{array}{r}204 \\
-102 \\
-102\end{array}$ & {$\left[\begin{array}{l}0.966 \\
0 \\
0.260\end{array}\right.$} & $\begin{array}{l}0 \\
1 \\
0\end{array}$ & $\left.\begin{array}{c}-0.260 \\
0 \\
0.966\end{array}\right]$ & 15.0 & $\begin{array}{r}-15 \\
-14 \\
29\end{array}$ & {$\left[\begin{array}{l}1 \\
0 \\
0\end{array}\right.$} & $\begin{array}{l}0 \\
0.966 \\
0.259\end{array}$ & $\left.\begin{array}{l}0 \\
0.259 \\
-0.966\end{array}\right]$ & 15.0 \\
\hline $\begin{array}{l}\text { UHF } \\
\text { 4-31 G(*) }\end{array}$ & $\begin{array}{l}B_{x x} \\
B_{y y} \\
B_{z z}\end{array}$ & $\begin{array}{r}-75 \\
-37 \\
113\end{array}$ & $\begin{array}{r}282 \\
-143 \\
-139\end{array}$ & {$\left[\begin{array}{l}0.967 \\
0 \\
0.255\end{array}\right.$} & $\begin{array}{l}0 \\
1 \\
0\end{array}$ & $\left.\begin{array}{c}-0.255 \\
0 \\
0.967\end{array}\right]$ & 14.8 & $\begin{array}{r}-23 \\
-19 \\
42\end{array}$ & {$\left[\begin{array}{l}1 \\
0 \\
0\end{array}\right.$} & $\begin{array}{l}0 \\
0.968 \\
0.249\end{array}$ & $\left.\begin{array}{l}0 \\
0.249 \\
-0.968\end{array}\right]$ & 14.4 \\
\hline $\begin{array}{l}\text { UHF+AN } \\
4-31 G(*)\end{array}$ & $\begin{array}{l}B_{x x} \\
B_{y y} \\
B_{z z}\end{array}$ & $\begin{array}{r}-56 \\
-43 \\
99\end{array}$ & $\begin{array}{r}216 \\
-109 \\
-107\end{array}$ & {$\left[\begin{array}{l}0.962 \\
0 \\
0.274\end{array}\right.$} & $\begin{array}{l}0 \\
1 \\
0\end{array}$ & $\left.\begin{array}{l}-0.274 \\
0 \\
0.962\end{array}\right]$ & 15.9 & $\begin{array}{r}-18 \\
-15 \\
33\end{array}$ & {$\left[\begin{array}{l}1 \\
0 \\
0\end{array}\right]$} & $\begin{array}{l}0 \\
0.956 \\
0.293\end{array}$ & $\left.\begin{array}{l}0 \\
0.293 \\
-0.956\end{array}\right]$ & 17.0 \\
\hline $\begin{array}{l}\text { Experiment } \\
\text { (ref. 3) }\end{array}$ & $\begin{array}{l}B_{x x x} \\
B_{y y y} \\
B_{z z}\end{array}$ & $\begin{array}{l}-64 \\
-64 \\
128\end{array}$ & {$\left[\begin{array}{l}162 \\
-81 \\
-81\end{array}+\right.$} & $\left.\begin{array}{r}-24 \\
-24 \\
48\end{array}\right]$ & & & & $\begin{array}{r}-15 \\
-15 \\
29\end{array}$ & & & & \\
\hline
\end{tabular}

The coordinate system $x, y, z$ is given in Fig. 1 . T represents the transformation matrix and gives the directions of the principal values $\left(B_{p_{p}}\right), \theta$ is the angle between the direction of the largest principal value and the nearest coordinate axis. ( $\theta^{\mathrm{a}}$ relative to $x ; \theta^{\mathrm{e}}$ relative to $z$ ).

[21]. All phosphoranyl and phosphorane anion radicals with experimentally known anisotropic couplings possess such an axially symmetrical dipolar hfc tensor [2-5]. Table $5\left(C_{2 v} \quad \dot{\mathrm{PH}}_{4}\right)$ and Table $6\left(C_{2 \mathrm{v}} \dot{\mathrm{P}} \mathrm{F}_{4}\right)$ reveal that the condition for an axially symmetrical system is only fulfilled when ROHF calculations are employed and thus $\left\langle S^{2}\right\rangle=0.75$. A Mulliken population analysis (Table 9) nicely illustrates the contaminating effect. Upon improvement of the doublet state the large negative value for the spin 


\section{TABLE 7}

Calculated phosphorus and fluorine dipolar hfe (B) for $C_{3 \mathrm{v}} \dot{\mathrm{PF}}_{4}$ using different computational methods ${ }^{a}$

\begin{tabular}{|c|c|c|c|c|c|c|c|c|}
\hline & & $\underline{\mathbf{P}}$ & $F^{\mathfrak{a}}$ & $\mathbf{F}_{1}^{\mathbf{e}}$ & & & & \\
\hline & & $B$ & $B$ & $B$ & & $\mathbf{T}$ & & $\theta^{\mathbf{e}}$ \\
\hline $\begin{array}{l}\text { UHF } \\
4-31 G\end{array}$ & $\begin{array}{l}B_{x x} \\
B_{y y} \\
B_{z z}\end{array}$ & $\begin{array}{r}-57 \\
-\mathbf{5 7} \\
\mathbf{1 1 5}\end{array}$ & $\begin{array}{r}10 \\
10 \\
-20\end{array}$ & $\begin{array}{r}280 \\
-145 \\
-135\end{array}$ & {$\left[\begin{array}{l}0.949 \\
0 \\
-0.317\end{array}\right.$} & $\begin{array}{l}0 \\
1 \\
0\end{array}$ & $\left.\begin{array}{l}0.317 \\
0 \\
0.949\end{array}\right]$ & 18.5 \\
\hline $\begin{array}{l}\mathrm{UHF}+\mathrm{AN} \\
4-31 \mathrm{G}\end{array}$ & $\begin{array}{l}B_{x x} \\
B_{y y} \\
B_{z z}\end{array}$ & $\begin{array}{r}-43 \\
-43 \\
87\end{array}$ & $\begin{array}{r}2 \\
2 \\
-3\end{array}$ & $\begin{array}{r}208 \\
-106 \\
-102\end{array}$ & {$\left[\begin{array}{l}0.943 \\
0 \\
-0.334\end{array}\right.$} & $\begin{array}{l}0 \\
1 \\
0\end{array}$ & $\left.\begin{array}{l}0.334 \\
0 \\
0.943\end{array}\right]$ & 19.5 \\
\hline $\begin{array}{l}\text { ROHF } \\
4-31 G\end{array}$ & $\begin{array}{l}B_{x x} \\
B_{y y} \\
B_{z z}\end{array}$ & $\begin{array}{r}-41 \\
-41 \\
83\end{array}$ & $\begin{array}{r}-2 \\
-2 \\
5\end{array}$ & $\begin{array}{r}154 \\
-77 \\
-77\end{array}$ & {$\left[\begin{array}{l}0.933 \\
0 \\
-0.359\end{array}\right.$} & $\begin{array}{l}0 \\
1 \\
0\end{array}$ & $\left.\begin{array}{l}0.359 \\
0 \\
0.933\end{array}\right]$ & 21.0 \\
\hline $\begin{array}{l}\text { UHF } \\
4-31 G(*)\end{array}$ & $\begin{array}{l}B_{x x} \\
B_{y y} \\
B_{z z}\end{array}$ & $\begin{array}{l}-57 \\
-57 \\
114\end{array}$ & $\begin{array}{r}-1 \\
-1 \\
2\end{array}$ & $\begin{array}{r}229 \\
-117 \\
-112\end{array}$ & {$\left[\begin{array}{l}0.938 \\
0 \\
-0.345\end{array}\right.$} & $\begin{array}{l}0 \\
1 \\
0\end{array}$ & $\left.\begin{array}{l}0.345 \\
0 \\
0.938\end{array}\right]$ & 20.2 \\
\hline $\begin{array}{l}\text { UHF + AN } \\
4-31 G\left({ }^{*}\right)\end{array}$ & $\begin{array}{l}B_{x x x} \\
B_{y y} \\
B_{z z}\end{array}$ & $\begin{array}{r}-48 \\
-48 \\
96\end{array}$ & $\begin{array}{r}-2 \\
-2 \\
4\end{array}$ & $\begin{array}{l}170 \\
-86 \\
-84\end{array}$ & {$\left[\begin{array}{l}0.931 \\
0 \\
-0.364\end{array}\right.$} & $\begin{array}{l}0 \\
1 \\
0\end{array}$ & $\left.\begin{array}{l}0.364 \\
0 \\
0.931\end{array}\right]$ & 21.4 \\
\hline
\end{tabular}

a Parameters as for Table 6 , except $\theta^{\mathrm{e}}$, the angle between the direction of the largest principal value of $F^{e}$ and the $x$-axis.

\section{TABLE 8}

Calculated phosphorus and fluorine dipolar hfc (B) for $C_{4 \mathrm{v}} \dot{\mathrm{PF}}_{5}^{-}$using different computational methods ${ }^{\mathrm{a}}$

\begin{tabular}{|c|c|c|c|c|c|c|c|c|}
\hline & & $\mathbf{P}$ & $F^{\mathbf{a}}$ & $\mathrm{F}_{1}^{\mathbf{e}}$ & & & & \\
\hline & & $B$ & $B$ & $B$ & & $\mathbf{T}$ & & $\theta^{\mathbf{e}}$ \\
\hline $\begin{array}{l}\text { UHF } \\
4-31 G\end{array}$ & $\begin{array}{l}B_{x x} \\
B_{y y} \\
B_{z z}\end{array}$ & $\begin{array}{r}-57 \\
-57 \\
114\end{array}$ & $\begin{array}{r}5 \\
5 \\
-10\end{array}$ & $\begin{array}{l}171 \\
-86 \\
-85\end{array}$ & {$\left[\begin{array}{l}0.914 \\
0 \\
-0.407\end{array}\right.$} & $\begin{array}{l}0 \\
1 \\
0\end{array}$ & $\left.\begin{array}{l}0.407 \\
0 \\
0.914\end{array}\right]$ & 24.0 \\
\hline $\begin{array}{l}\text { UHF+ AN } \\
4-31 G\end{array}$ & $\begin{array}{l}B_{x x} \\
B_{y y} \\
B_{z z}\end{array}$ & $\begin{array}{r}-49 \\
-49 \\
98\end{array}$ & $\begin{array}{r}1 \\
1 \\
-2\end{array}$ & $\begin{array}{r}128 \\
-64 \\
-64\end{array}$ & {$\left[\begin{array}{l}0.911 \\
0 \\
-0.413\end{array}\right.$} & $\begin{array}{l}0 \\
1 \\
0\end{array}$ & $\left.\begin{array}{l}0.413 \\
0 \\
0.911\end{array}\right]$ & 24.4 \\
\hline $\begin{array}{l}\text { UHF } \\
4-31 G(*)\end{array}$ & $\begin{array}{l}B_{x x} \\
B_{y y} \\
B_{z z}\end{array}$ & $\begin{array}{r}-57 \\
-57 \\
114\end{array}$ & $\begin{array}{r}-1 \\
-1 \\
2\end{array}$ & $\begin{array}{l}142 \\
-72 \\
-70\end{array}$ & {$\left[\begin{array}{l}0.907 \\
0 \\
-0.420\end{array}\right.$} & $\begin{array}{l}0 \\
1 \\
0\end{array}$ & $\left.\begin{array}{l}0.420 \\
0 \\
0.907\end{array}\right]$ & 24.8 \\
\hline $\begin{array}{l}\text { UHF + AN } \\
4-31 G(*)\end{array}$ & $\begin{array}{l}B_{x x} \\
B_{y y} \\
B_{z z}\end{array}$ & $\begin{array}{r}-52 \\
-52 \\
103\end{array}$ & $\begin{array}{r}-3 \\
-3 \\
5\end{array}$ & $\begin{array}{l}106 \\
-53 \\
-53\end{array}$ & {$\left[\begin{array}{l}0.902 \\
0 \\
-0.432\end{array}\right.$} & $\begin{array}{l}0 \\
1 \\
0\end{array}$ & $\left.\begin{array}{l}0.432 \\
0 \\
0.902\end{array}\right]$ & 25.6 \\
\hline
\end{tabular}

aparameters as for Table 7. 
Mulliken population analysis for the two $C_{2 v}$ radicals using different calculational methods. Values are computed as a summation of the inner and outer orbitals of the 4-31G basis set $\left(\left\langle S^{2}\right\rangle\right.$ values are given for comparison)

\begin{tabular}{|c|c|c|c|c|c|c|}
\hline & \multicolumn{3}{|l|}{$C_{2 \mathrm{~V}} \dot{\mathrm{P}} \mathrm{H}_{4}$} & \multicolumn{3}{|l|}{$C_{2 \mathrm{v}} \dot{\mathrm{P}} \mathrm{F}_{4}$} \\
\hline & UHF & $\mathrm{UHF}+\mathrm{AN}$ & ROHF & UHF & $\mathrm{UHF}+\mathrm{AN}$ & ROHF \\
\hline$\left\langle S^{2}\right\rangle$ & 0.8080 & 0.7506 & 0.7500 & 0.7773 & 0.7503 & 0.7500 \\
\hline $3 s$ & 0.052 & 0.076 & 0.105 & 0.289 & 0.302 & 0.328 \\
\hline $3 p_{x}$ & -0.324 & -0.104 & 0.000 & -0.089 & -0.030 & 0.000 \\
\hline $3 p_{y}^{x}$ & 0.041 & 0.015 & 0.000 & 0.015 & 0.005 & 0.000 \\
\hline $3 p_{z}$ & 0.202 & 0.168 & 0.187 & 0.314 & 0.291 & 0.313 \\
\hline
\end{tabular}

density in the $3 p_{x}$ orbital diminishes and becomes zero when the ROHF procedure is used. The fact that the $C_{3 \mathrm{v}}$ and $C_{4 \mathrm{v}}$ radicals possess an axially symmetrical phosphorus dipolar hfc in all calculations is a consequence of the higher rotational symmetry of the radical. Only for the $C_{2 \mathrm{v}} \dot{\mathrm{PF}}_{4}$ radical anisotropic experimental data are available for a direct comparison [3] (Table 6). The computed phosphorus dipolar hfc is in reasonable agreement with the experimental data and the couplings of the two equatorial fluorines are almost perfectly predicted. Hasegawa et al. [3] report two anisotropic parts for each of the two equivalent apical fluorines because of an asymmetric hyperfine tensor with principal values along the $x$ and $z$ axes. Our calculations do not confirm this result but clearly show an axially symmetrical tensor. However, the computations reveal that the largest principal value is not coincident with any of the $x, y$ or $z$ axes, but lies in the $x, z$ plane. Since the single crystal experiments on the $\dot{\mathrm{P}} \mathrm{F}_{4}$ radical consisted of rotation around only one axis it is possible that the true principal values could not be traced, and thus the reported non-axial symmetry is in error. The phosphorus dipolar hfcs of the other calculated radicals also possess values that are similar to experimentally known anisotropic couplings $\left(B_{z z}^{P}=70-130 \mathrm{G}\right)[2]$.

The implementation of $d$-functions results in a small rise of the phosphorus dipolar hfc tensor. The largest effects are found for the two $\dot{\mathrm{P}}_{4}$ radicals where an increase of $13-14 \mathrm{G}$ is found on UHF+AN-level. The influence of the second-order Gaussians is more pronounced on the dipolar couplings of the most contributing ligands. A serious decrease of the largest principal hfc is calculated for the apical fluorines of $C_{2 \mathrm{v}} \dot{\mathrm{PF}}_{4}$ and the equatorial fluorines of $C_{3 \mathrm{v}} \dot{\mathrm{PF}}_{4}$ and $C_{4 \mathrm{v}} \dot{\mathrm{P}} \mathrm{F}_{5}^{-}$.

An important and unexpected result that can be derived from Table 6 to 8 is that the direction of fluorine dipolar hfc does not coincide with an axis of the coordinate system, nor with the $\mathrm{P}-\mathrm{F}$ bond, but makes a pronounced angle with the direction of this bond. This is illustrated in Fig. 2 for the fluorine containing radicals. Figure 2 is based on the ROHF calculations for $\dot{\mathrm{PF}}_{4}$ and the UHF+AN calculation for $\dot{\mathrm{PF}}_{5}{ }^{-}$. The angles $\theta$ between 

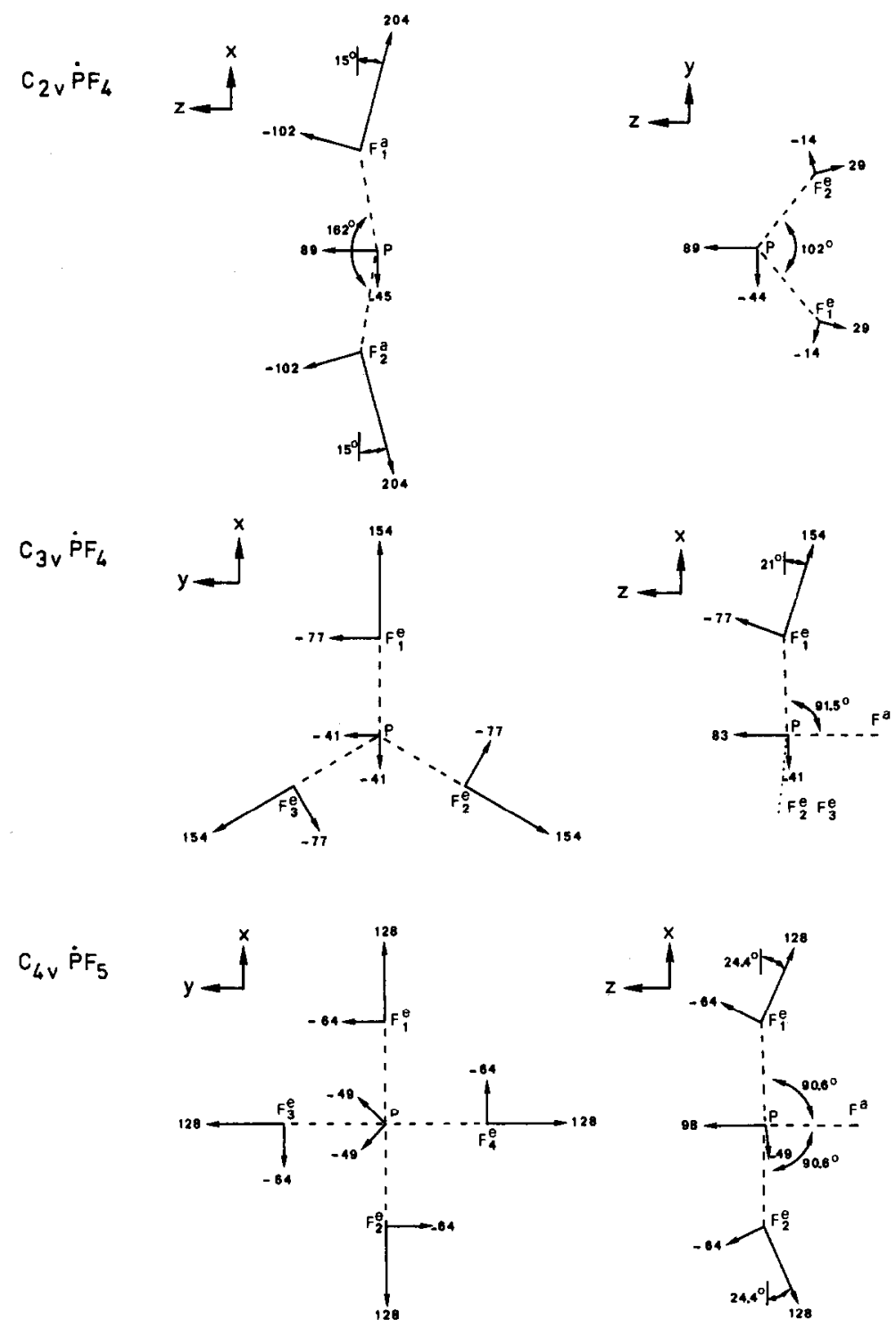

Fig. 2. Directions of the dipolar hfes for the $C_{2 \mathrm{v}} \dot{\mathrm{P}} \mathrm{F}_{4}, C_{3 \mathrm{v}} \dot{\mathrm{P} F_{4}}$ and $C_{4 \mathrm{v}} \dot{\mathrm{P} F} \mathrm{~F}_{5}^{-}$radicals (see Tables 6 to 8 ).

the direction of the fluorine dipolar hfc and the axes of the coordinate system are given in the last column of Tables 6 to 8 .

Spin density plots

We have plotted the point spin density $\rho(\overrightarrow{\mathrm{r}})$ for the $C_{2 \mathrm{v}} \dot{\mathrm{P}} \mathrm{H}_{4}$ and $C_{2 \mathrm{v}}$ $\dot{\mathrm{PF}}_{4}$ radicals. The spin density plots were calculated in the $x, z$ and $y, z$ 
planes. The values at the curves of constant spin density in Figs. 3 and 4 are expressed in milli-electrons bohr ${ }^{-3}$. The wave function used in these calculations was derived from the ROHF procedure to minimize contaminating effects. Figure 4 aptly illustrates the results concerning the direction of the apical fluorine dipolar hfc since it is clear that the plotted fluorine $2 p$

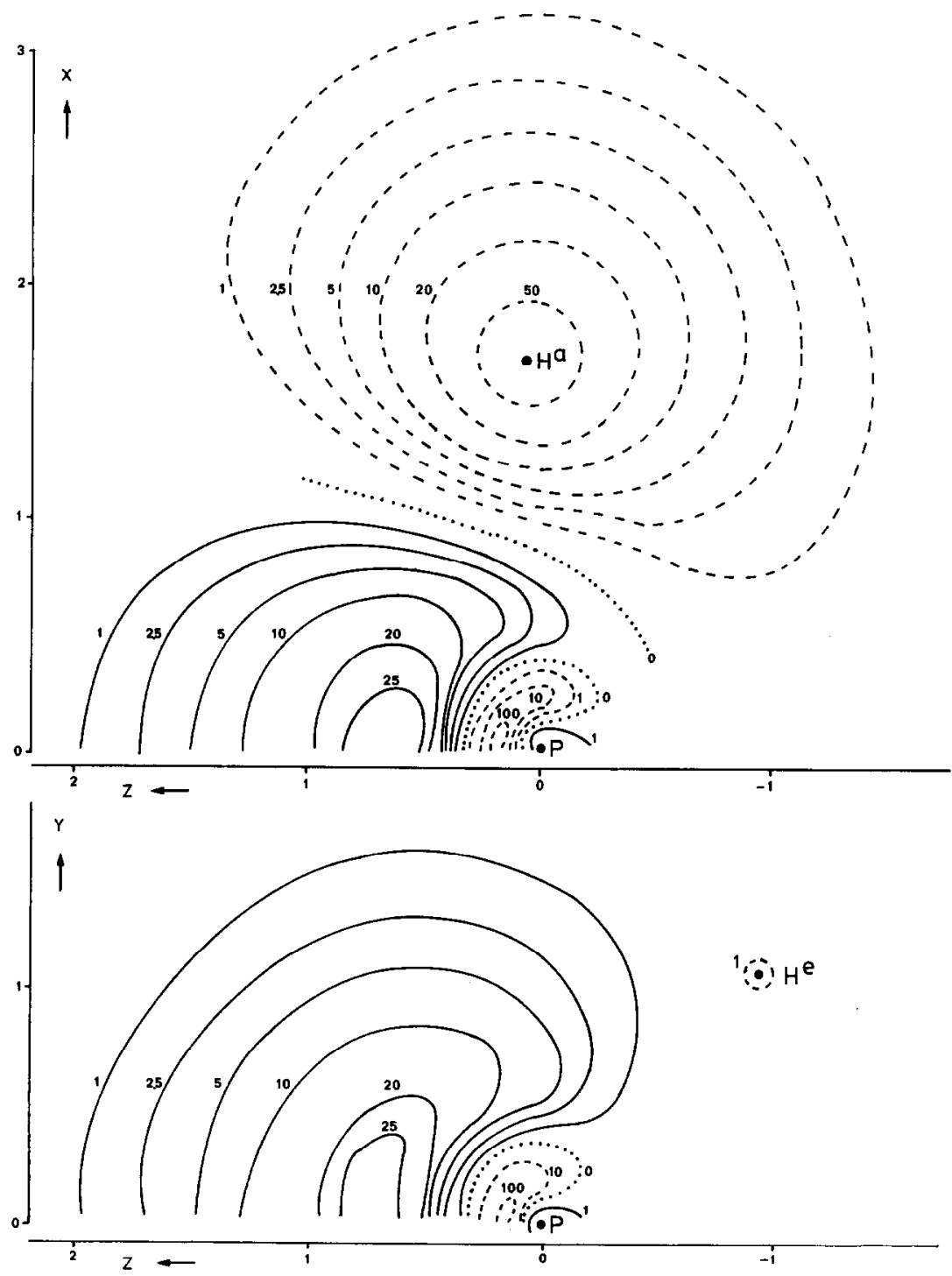

Fig. 3. Spin density plot of $C_{2 v} \dot{\mathrm{P}} \mathrm{H}_{4}$ calculated in the $x, z$ and $y, z$ planes with the 4-31G ROHF wave function. Because of the twofold $\left(C_{2 v}\right)$ symmetry only the positive $x$ and $y$ directions are shown. The values of the spin density at the curves are in milli-electrons bohr ${ }^{-3}$. 

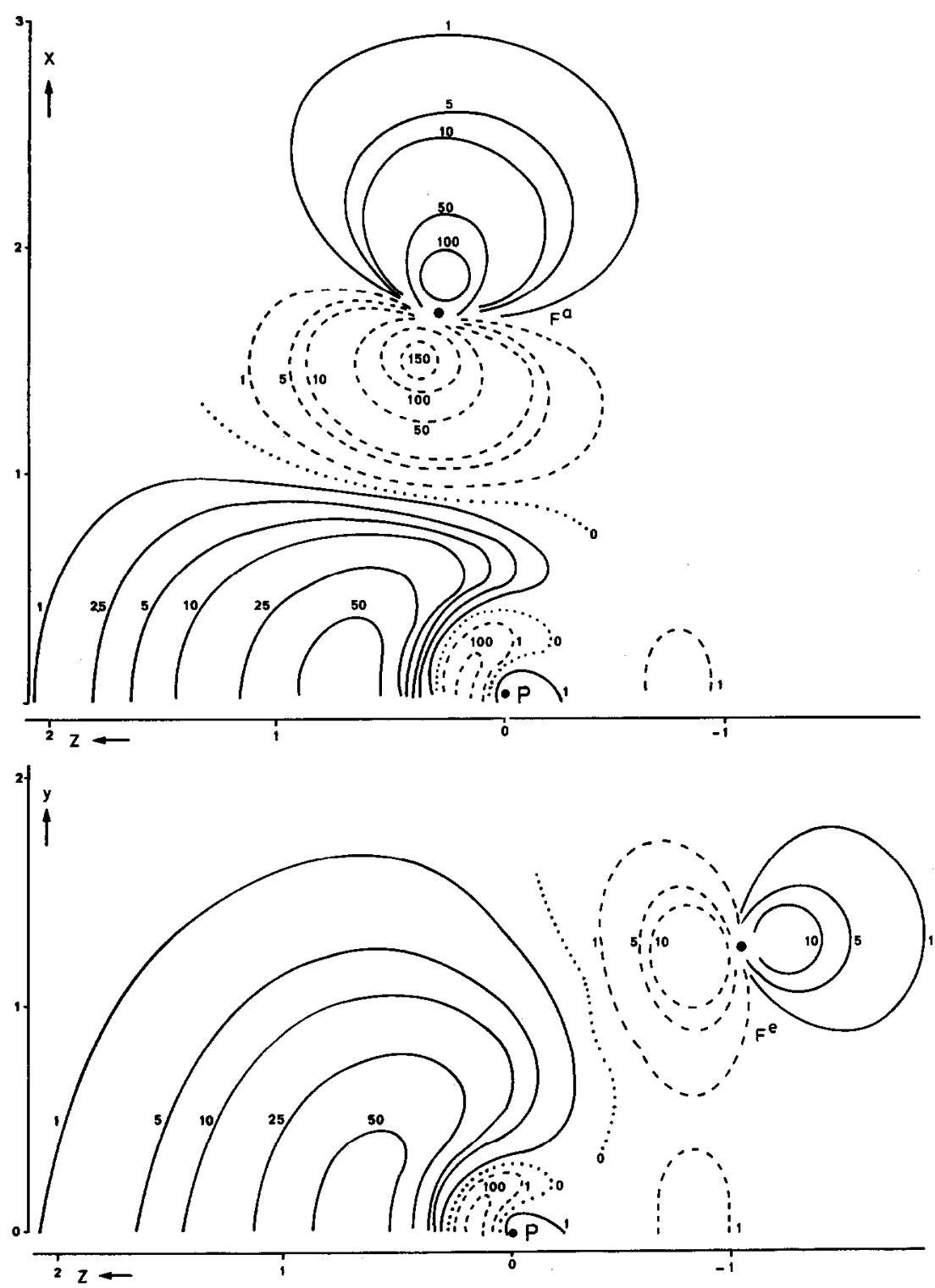

Fig. 4. Spin density plot of $C_{2 v} \dot{\mathrm{P} F}$, calculated in the $x, z$ and $y, z$ planes with the 4-31G ROHF wave function. Because of the two-fold $\left(C_{2 v}\right)$ symmetry only the positive $x$ and $y$ directions are shown. The values of the spin density at the curves are in milli-electrons bohr ${ }^{-3}$. 
orbital is not directed along the $P-F$ bond. Figures 3 and 4 furthermore emphasize the antibonding character of the SOMO of phosphoranyl radicals.

\section{DISCUSSION}

All computational methods give fairly good results for the isotropic hfc. For the dipolar hfc, however, the wave function must present a pure spin state in order to produce axially symmetrical hyperfine tensors and to predict experimental couplings. Further improvement of the accuracy of the calculation of isotropic and anisotropic hfc can be achieved by the use of more accurate and larger basis sets. Especially the behaviour of the wave function near the nuclei is of major importance since both isotropic $\left(\delta\left(\vec{r}_{N}\right)\right)$ and dipolar $\left(\left\langle r^{-3}\right\rangle\right)$ hfc strongly depend on the electron distribution close to the nuclei. Comparison of the isotropic and anisotropic phosphorus hfe for the $C_{2 v}$ and $C_{3 v}$ radicals of $\dot{P H}_{4}$ and $\dot{P} F_{4}$ indicate that their magnitude is comparable for both isomers of the $\mathrm{PH}_{4}$ and $\dot{\mathrm{PF}}_{4}$ radical respectively. The same result was experimentally demonstrated by Hamerlinck et al. [22, 23] in a single crystal ESR study of the TBP-e $\left(C_{2 \mathrm{v}}\right)$ and TBP-a $\left(C_{3 \mathrm{v}}\right)$ isomers of

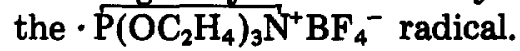

The calculations predict larger hfc for the $C_{\mathrm{3v}}$ isomers, whereas the reverse was found experimentally (Fig. 5). The strong dependency of the isotropic hfc on variation of the apical-equatorial bond angle $\phi$ in $C_{3 \mathrm{v}}$ and $C_{4 \mathrm{v}}$ radicals [24] can partly account for this discrepancy. Another explanation may be found in the participation of $d$ orbitals. It was shown that the inclusion of $d$-type Gaussians leads to an increase of the isotropic phosphorus hfc for the $C_{2 v}$ radicals, but lowers this value for $C_{3 v}$ radicals. The $d$-type Gaussians further affect the hyperfine interaction of the unpaired electron with the ligand nuclei. For those ligands that contribute most to the SOMO the hyperfine couplings are lowered: for hydrogen the isotropic hfc and for fluorine the anisotropic hfc. This can be explained by the new type of symmetry which is introduced on phosphorus by the inclusion of $d$ orbitals, and which

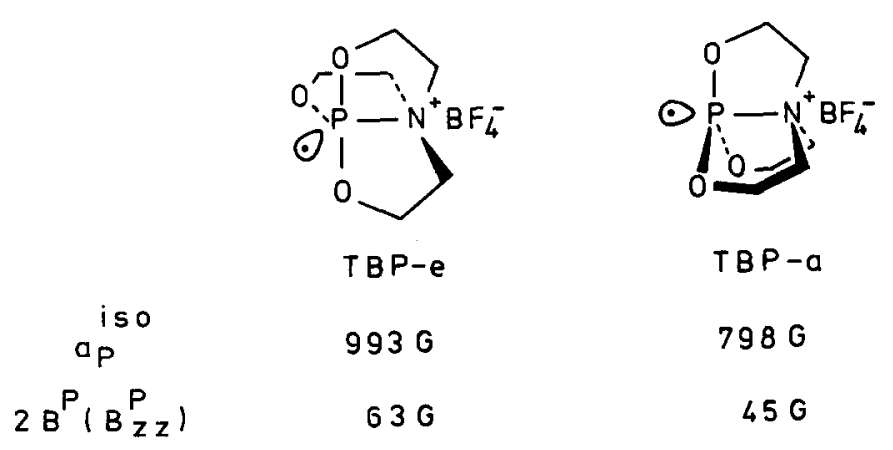

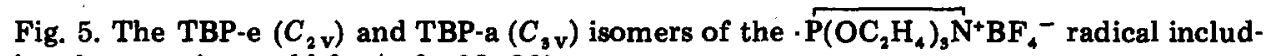
ing the experimental hfes (refs. 22, 23). 
TABLE 10

The $d$ orbital SOMO coefficients for the studied radicals resulting from a 4-31G(*) UHF calculation

\begin{tabular}{llllllll}
\hline & & \multicolumn{1}{c}{$d_{x x}$} & \multicolumn{1}{c}{$d_{y y}$} & $d_{z z}$ & $d_{x y}$ & $d_{x z}$ & $d_{y z}$ \\
\hline$\dot{\mathrm{P}} \mathrm{H}_{4}$ & $C_{2 \mathrm{v}}$ & -0.115 & 0.062 & 0.069 & 0 & 0 & 0 \\
$\dot{\mathrm{PH}}_{4}$ & $C_{3 \mathrm{v}}$ & -0.033 & -0.033 & 0.065 & 0 & 0 & 0 \\
$\dot{\mathrm{PF}}_{4}$ & $C_{2 \mathrm{v}}$ & -0.100 & 0.008 & 0.195 & 0 & 0 & 0 \\
$\dot{\mathrm{PF}}_{4}$ & $C_{3 \mathrm{v}}$ & -0.055 & -0.055 & 0.134 & 0 & 0 & 0 \\
$\dot{\mathrm{PF}}_{\mathrm{s}}-$ & $C_{4 \mathrm{v}}$ & -0.067 & -0.067 & 0.144 & 0 & 0 & 0 \\
\hline
\end{tabular}

fits exactly to the symmetry of the SOMO of the phosphoranyl radicals. The computed MO coefficients (Table 10) indicate that from the six secondorder Gaussians the $d_{x x}$ and $d_{x z}$ orbitals contribute most to the SOMO of the $C_{2 \mathrm{v}}$ radicals and $d_{x x}, d_{y y}$ and $d_{z x}$ to the SOMO of the $C_{3 \mathrm{v}}$ and $C_{4 \mathrm{v}}$ radicals. The $d_{x y}, d_{x z}$ and $d_{y z}$ orbitals do not contribute to any of the SOMOs because of their wrong symmetry.

The fact that the calculated dipolar fluorine hfc is not coincident with the corresponding fluorine-phosphorus bond is a new aspect in the structures of these radicals. This result remains unaffected after the introduction of $d$ orbitals. Single crystal ESR studies on $\dot{\mathrm{POCl}}_{3}^{-}$[5] and $\mathrm{PF}_{4}$ [3] have demonstrated that the apical ligands of these radicals are magnetically equivalent for all orientations of the radical relative to the external magnetic field. Subsequently the conclusion was drawn that the $\mathrm{X}^{\mathrm{a}}-\mathrm{P}-\mathrm{X}^{\mathrm{a}}$ bond is linear. In view of our calculations this conclusion seems unjustifiable since the dipolar hyperfine tensors of the apical ligands can be aligned even when the $\mathrm{X}^{\mathrm{a}}-\mathrm{P}-\mathrm{X}^{\mathrm{a}}$ bond angle deviates seriously from $180^{\circ}$. An explanation for these results can be found in the fact that phosphoranyl and phosphorane anion radicals are hypervalent, i.e., there are more than eight electrons around phosphorus. The SOMO will therefore possess antibonding character, and is not responsible for the bonding of phosphorus to the ligands.

\section{ACKNOWLEDGEMENT}

This investigation has been supported by the Netherlands Foundation for Chemical Research (SON) with financial aid from the Netherlands Organization for the Advancement of Pure Research (ZWO). We kindly thank Dr. G. J. Visser, Computing Center of the Eindhoven University of Technology, The Netherlands, for adapting GAUSSIAN 80 [15] to the Burroughs B7700 computer. 


\section{REFERENCES}

1 For a review on phosphoranyl radicals see: W. G. Bentrude, Acc. Chem. Res., 15 (1982) 117.

2 J. H. H. Hamerlinck, P. Schipper and H. M. Buck, J. Am. Chem. Soc., 105 (1983) 385.

3 A. Hasegawa, K. Ohnishi, K. Sogabe and M. Miura, Mol. Phys., 30 (1975) 1367.

4 T. Berclaz, M. Geoffroy and E. A. C. Lucken, Chem. Phys. Lett., 36 (1975) 677.

5 T. Gillbro and F. Williams, J. Am. Chem. Soc., 96 (1974) 5032.

6 J. M. Howell and J. F. Olsen, J. Am. Chem. Soc., 98 (1976) 7119.

7 T. Clark, J. Comput. Chem., 4 (1983) 404.

8 T. Clark, J. Chem. Soc., Perkin Trans. 2, (1982) 1267.

9 T. Clark, J. Chem. Soc., Chem. Commun., (1981) 515.

10 A. T. Amos and G. G. Hall, Proc. R. Soc. London Ser., A, 263 (1961) 483.

11 A. T. Amos and L. C. Snyder, J. Chem. Phys., 41 (1964) 1773.

12 J. S. Binkley, J. A. Pople and P. A. Dobosh, Mol. Phys., 28 (1974) 1423.

13 (a) R. Ditchfield, W. J. Hehre and J. A. Pople, J. Chem. Phys., 54 (1971) 724.

(b) W. J. Hehre and W. A. Lathan, J. Chem. Phys., 56 (1972) 5255.

14 M. M. Francl, W. J. Pietro, W. J. Hehre, J. S. Binkley, M. S. Gordon, D. J. DeFrees and J. A. Pople, J. Chem. Phys., 77 (1982) 3654.

15 J. S. Binkley, R. A. Whiteside, R. Krishnan, R. Seeger, D. J. DeFrees, H. B. Schlegel, S. Topiol, L. R. Kahn and J. A. Pople, GAUSSIAN 80, Department of Chemistry, Carnegie-Mellon University, Pittsburgh.

16 P. Marsh and D. E. Williams, Q.C.P.E., Program No. 421, 1981.

17 D. B. Neumann, H. Basch, R. L. Kornegay and L. C. Snyder, Q.C.P.E. 11, Program No. 199, 1971.

18 Howell and Olsen (ref. 6) found a smaller energy lowering of $36.5 \mathrm{kcal} \mathrm{mol}^{-1}$ for $C_{2 \mathrm{v}}$ $\mathrm{PH}_{4}$ on implementation of $d$-type functions with a radial exponent of 0.36 .

19 A. J. Colussi, J. R. Morton and K. F. Preston, J. Chem. Phys., 62 (1975) 2004.

20 J. R. Morton, K. F. Preston and S. J. Strach, J. Magn. Reson., 37 (1980) 321.

21 R. S. Drago, Physical Methods in Chemistry, W. B. Saunders, London, 1977.

22 J. H. H. Hamerlinck, P. Schipper and H. M. Buck, J. Chem. Soc., Chem Commun., (1981) 1149.

23 J. H. H. Hamerlinck, P. Schipper and H. M. Buck, J. Org. Chem., 48 (1983) 306.

24 R. A. J. Janssen, G. J. Visser and H. M. Buck, J. Am. Chem. Soc., 106 (1984) 3429. 